\title{
How much more can minimally invasive surgery be minimized? Mini-laparoscopic Nissen fundoplication in adults
}

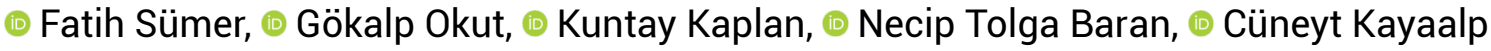 \\ Department of General Surgery, Inonu University Turgut Ozal Medical Center, Malatya, Turkey
}

\begin{abstract}
Introduction: Mini-laparoscopy has become a current issue as a minimally invasive technique in gastroesophageal reflux surgery, which does not require specimen extraction. There are a limited number of cases of Nissen fundoplication performed in the adult age group using the mini-laparoscopic method. In this article, our aim is to draw attention to the fact that mini-laparoscopy is a preferable technique in Nissen fundoplication surgery.
\end{abstract}

Materials and Methods: Seven patients underwent mini-laparoscopic Nissen fundoplication between January 2010 and December 2019. Demographic data and perioperative parameters were analyzed retrospectively.

Results: Three of our patients (43\%) were female and the average age of our patients was $45.4 \pm 11.1$. All patients presented with complaints of heartburn and regurgitation. There was Barrett metaplasia in the pathology results and no dysplasia was observed in any patient. Mean operation time was $117 \pm 49.9$ min, bleeding amount was $<10 \mathrm{ml}$ in all surgeries. The median time to oral intake was $8^{\text {th }}$ post-operative $h$, and no complications developed in any of our patients. In the post-operative period, there was no need for narcotic analgesic, after a single dose of nonsteroidal anti-inflammatory drugs, the treatment was continued with two doses of oral analgesic. Median length of stay hospital was $3(2-4)$ days, the median follow-up period was 67 (29-120) months.

Conclusion: Anti-reflux surgery can be easily performed, mini-laparoscopically since it is not a resective surgical procedure. It can provide advantages such as better cosmesis, less port site complications, and less analgesic use.

Keywords: Gastroesophageal reflux disease; mini-laparoscopy; Nissen fundoplication.

\section{Introduction}

Laparoscopic methods have gained rapid acceleration in the past two decades and entered many areas in surgery. It is safely applied in resective, reconstructive, or functional surgical procedures. Mini-laparoscopy has become a current issue as a minimally invasive technique in gastroesophageal reflux surgery, which does not require specimen extraction. When the literature was reviewed, Razumovski et al. from Russia published that they safely use mini-laparoscopy in anti-reflux procedures in children. ${ }^{[1]}$ Later, Dimbarre et al. described a mini-laparoscopic method for Nissen fundoplication in the adult group. ${ }^{[2]}$ 
We also performed a mini-laparoscopic Nissen fundoplication operation on seven patients with gastroesophageal reflux disease. In this article, our aim is to draw attention to the fact that mini-laparoscopy is a preferable technique in Nissen fundoplication surgery.

\section{Materials and Methods}

Seven patients underwent mini-laparoscopic Nissen fundoplication between January 2010 and December 2019 at İnönü University Turgut Özal Medical Center General Surgery Department approved by the ethics committee. Demographic data and perioperative parameters were analyzed retrospectively. Continuous variables were defined as median (range) and categorical data were defined as frequencies and percentages.

\section{Surgical Technique}

The patients were operated in the French position under general anesthesia. Operative monitoring was performed by the anesthesia team. A nasogastric tube was then placed. The surgeon worked between the patient's leg. The camera assistant helped the surgeon from the right of the patient. Pneumoperitoneum was provided with $\mathrm{CO} 2$ in a way that intra-abdominal pressure was $14 \mathrm{mmHg}$ by passing through the layers with a Veress needle from the midline $4 \mathrm{~cm}$ above the umbilicus. The Veress needle was removed and a $5 \mathrm{~mm}$ trocar and $5 \mathrm{~mm}$ scope was inserted into the abdomen and explored. The abdomen was entered using a $5 \mathrm{~mm}$ trocar under the xiphoid. The trocar was removed from here and an automatic liver retractor was entered. Two $5 \mathrm{~mm}$ working trocars were inserted $4 \mathrm{~cm}$ below the xiphoid, right and left mid-clavicular. In addition, the 5th trocar was entered for retraction at the left mid-axillary line at the umbilical level. All trocars were $5 \mathrm{~mm}$ in size and were studied mini laparoscopically with a $5 \mathrm{~mm}$ camera and surgical instruments (Fig. 1). The patient was placed in approximately 15 degrees Trendelenburg position. The esophagus was freed by protecting the vagus. The esophagus was suspended in front of the right and left diaphragmatic cruses. The space between the diaphragmatic cruses was closed with two sutures. The greater curvature from the level of the stomach corpus to the cardia was released. The fundus was passed posteriorly to surround the esophagus $360^{\circ}$. Fundus was fixed with three anterior sutures. One of the sutures was fixed to the esophagus by passing a suture from the distal esophagus to prevent the fundoplication from slipping onto the thorax or stomach.

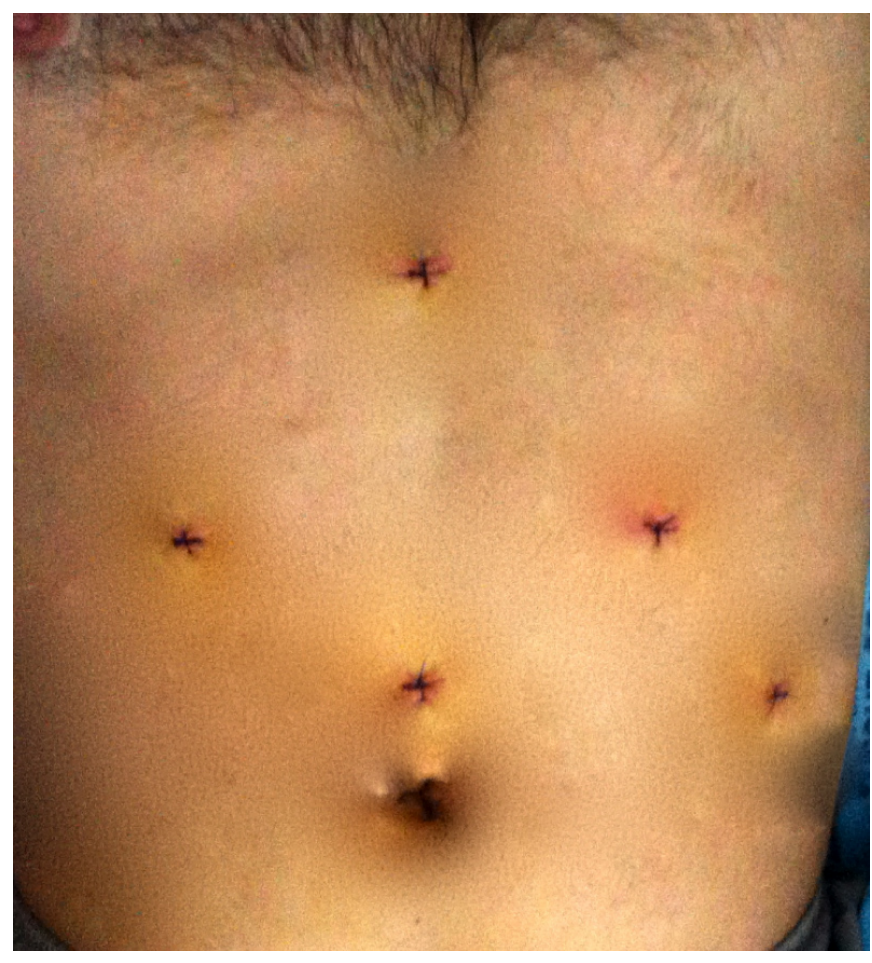

Figure 1. Postoperative $2^{\text {nd }}$ day view of trocar sites.

\section{Results}

Three of our patients (\%) were female and the average age of our patients was $45.4 \pm 11.1$. All patients presented with complaints of heartburn and regurgitation. Atypical symptoms such as hoarseness and cough accompanied in our three patients. Median reflux symptom durations were 10 (7-17) years. Esophagitis was detected in all patients on upper digestive system endoscopy. There was Barrett metaplasia in the pathology results and no dysplasia was observed in any patient. Acid reflux diagnosis was confirmed with 24 $\mathrm{h}$ pH monitoring. Median DeMeester score was 26 (17.3-26), median BMI was 24 (24-26) $\mathrm{kg} / \mathrm{m}^{2}$. Mean operation time was $117 \pm 49.9 \mathrm{~min}$, bleeding amount was $<10 \mathrm{ml}$ in all surgeries. The median time to oral intake was 8 th post-operative hour, and no complications developed in any of our patients. In the post-operative period, there was no need for narcotic analgesic, and after a single post-operative dose of NSAI, two doses of oral analgesic treatment were started. Median length of stay hospital was 3(2-4) days, the median follow-up period was 67 (29-120) months, and no problem was observed in any patient.

\section{Discussion}

Advances in laparoscopic surgery have prompted surgeons to seek more minimal technique. Minimally invasive surgery through smaller ports has come to the fore, especially in functional surgical procedures that do not require spec- 
imen resection and extraction. When the literature is reviewed, today many surgical procedures can be performed as mini-laparoscopic, including the cases requiring organ resection. ${ }^{[4,5]}$ Laparoscopic Nissen fundoplication is accepted as the gold standard in case of surgical indication in gastroesophageal reflux disease. ${ }^{[6]}$ It is traditionally made using $2.10 \mathrm{~mm}$ and $3.5 \mathrm{~mm}$ ports. However, with the use of a $10 \mathrm{~mm}$ port, the risk of developing problems related to both esthetics and incision increases. The risk of pain and trocar hernia increases, especially in port places of $10 \mathrm{~mm}$ and larger. In addition, a worse appearance occurs cosmetically. ${ }^{[7]}$ In the study conducted by Novitsky et al. for laparoscopic cholecystectomy in 2005, it was shown that mini-laparoscopy had positive effects on cosmesis, post-operative trocar site hernia, and post-operative pain. ${ }^{[8]}$ For this reason, it seems more advantageous to perform the surgery through 5 $\mathrm{mm}$ or smaller ports instead of $10 \mathrm{~mm}$. First, Razumovski et al. ${ }^{[1]}$ from Russia described mini-laparoscopic Nissen fundoplication in gastroesophageal reflux disease in children. In the largest study in the literature on mini-laparoscopic anti-reflux surgery in the adult population, Almond et al. used a $10 \mathrm{~mm}$ camera port, and this differs with our technique. ${ }^{[9]}$ We performed Nissen fundoplication surgery as mini-laparoscopically using $5.5 \mathrm{~mm}$ ports. Dimbarre et al., another study in the literature, used a $3 \mathrm{~mm}$ sized port, and there was a need for $7 \%$ larger port placement. Again in this study, the camera port is $10 \mathrm{~mm}$ in size. Considering that trocar site hernias after laparoscopic surgery originate from ports of up to $10 \mathrm{~mm}$ size, we think that our technique is more reliable in this sense. ${ }^{[10]}$ Trocar site hernia was not observed in any of our patients. It was observed that the need for analgesic was significantly less in the post-operative follow-up of the patients. In addition, smaller incisions at the $5 \mathrm{~mm}$ trocar sites provided better cosmesis. The fact that the port site is $<10 \mathrm{~mm}$ makes the fascia defect smaller. For this reason, the risk of developing port site hernia is much less. When compared with two similar studies, although our sample group was small, our follow-up time of was 67 (29-120) months may be significant in terms of long-term results of the mini-laparoscopic method.

\section{Conclusion}

Anti-reflux surgery can be easily performed mini-laparoscopically since it is not a resective surgical procedure. In this way, it can provide advantages such as better cosmesis, less port site complications, and less analgesic use. Considering these advantages, the mini-laparoscopic technique seems to be a safe and preferable method in laparoscopic anti-reflux surgery. Prospective studies to be carried out in large series are needed to say clearer advantages.

\section{Disclosures}

Ethichs Committee Approval: Seven patients underwent mini-laparoscopic Nissen fundoplication between January 2010 and December 2019 at İnönü University Turgut Özal Medical Center General Surgery Department approved by the ethics committee.

Peer-review: Externally peer-reviewed.

Conflict of Interest: None declared.

Authorship Contributions: Concept - F.S.,C.K.; Design F.S., G.O.; Supervision - F.S., C.K.; Materials - N.T.B., K.K.; Data collection and/or processing - K.K., N.T.B.; Analysis and/or interpretation - F.S., G.O.; Literature search - K.K., N.T.B.; Writing - G.O.; Critical review - F.S., C.K.

\section{References}

1. Razumovski AL, Alkhasov AB, Pavlov AA, Mitupov ZB, Mikhailova OA. Mini-laparoscopic fundoplication by nissen in the treatment of gastroesophageal reflux at children. Khirurgiia (Mosk) 2008;2:48-53.

2. Dimbarre D, de Loureiro PM, Claus C, Carvalho G, Trauczynski P, Elias F. Minilaparoscopic fundoplication: Technical adaptations and initial experience. Arq Gastroenterol 2012;49:223-6.

3. Neto RM, Herbella FA, Schlottmann F, Patti MG. Does DeMeester score still define GERD? Dis Esophagus 2019;32:doy118. [CrossRef]

4. Delgado-Sánchez E, Peay-Pinacho JA, Zapardiel I. Role of single-site and mini-laparoscopy in gynecologic surgery. Minerva Ginecol 2020;2020:04607-9. [CrossRef]

5. Sumer F, Kayaalp C, Polat Y, Ertugrul I, Karagul S. Transgastric removal of a polycystic liver disease using mini-laparoscopic excision. Interv Med Appl Sci 2016;8:89-92. [CrossRef]

6. Schlottmann F, Nurczyk K, Patti MG. Laparoscopic nissen fundoplication: How i do it? J Laparoendosc Adv Surg Tech A 2020;30:639-41. [CrossRef]

7. Tonouchi $\mathrm{H}$, Ohmori $\mathrm{Y}$, Kobayashi M, Kusunoki M. Trocar site hernia. Arch Surg 2004;139:1248-56. [CrossRef]

8. Novitsky YW, Kercher KW, Czerniach DR, Kaban GK, Khera S, Gallagher-Dorval KA, et al. Advantages of mini-laparoscopic vs conventional laparoscopic cholecystectomy: Results of a prospective randomized trial. Arch Surg 2005;140:117883. [CrossRef]

9. Almond LM, Charalampakis V, Mistry $\mathrm{P}$, Naqvi M, Hodson $\mathrm{J}$, Lafaurie $\mathrm{G}$, et al. An "all $5 \mathrm{~mm}$ ports" technique for laparoscopic day-case anti-reflux surgery: A consecutive case series of 205 patients. Int J Surg 2016;35:214-7. [CrossRef]

10. Gutierrez M, Stuparich M, Behbehani S, Nahas S. Does closure of fascia, type, and location of trocar influence occurrence of port site hernias? A literature review. Surg Endosc 2020;34:5250-8. [CrossRef] 